\title{
Diversidade genética em genótipos de Capsicum annuum L. (Solanaceae) promissores para uso ornamental
}

\section{Laís dos Santos Neri da Silva ${ }^{1}, *$, Gabriela Corrêa Morais ${ }^{2}$, Lucas da Silva Costa ${ }^{3}$, Jéssica Fernanda Ferreira dos Santos $^{2}$, Camila Maria Ribeiro da Silva Filha ${ }^{4}$ e Raimundo Nonato Oliveira Silva 5}

\footnotetext{
${ }^{1}$ Universidade Federal do Piauí. Programa de Pós-Graduação em Genética e Melhoramento. Campus Ministro Petrônio Portella. Bairro Ininga. Teresina-PI, Brasil (CEP 64049-550).*E-mail: silva.lsn@hotmail.com.

${ }^{2}$ Universidade Federal de Goiás. Escola de Agronomia. Programa de Pós-Graduação em Genética e Melhoramento de Plantas. Avenida Esperança, S/№. Campus Samambaia. Goiânia-GO, Brasil (CEP 74690-900).

${ }^{3}$ Universidade Estadual de Santa Cruz. Programa de Pós-Graduação em Genética e Biologia Molecular. Rodovia Jorge Amado, km 16. Salobrinho. Ilhéus-BA, Brasil (CEP 45662-900).

${ }^{4}$ Universidade Federal de Goiás. Instituto de Ciências Biológicas. Programa de Pós-Graduação em Genética e Biologia Molecular. Avenida Esperança, s/n. Campus Samambaia. Goiânia-GO, Brasil (CEP 74690-900).

5Universidade Federal do Piauí. Curso de Licenciatura em Ciências Biológicas. Rodovia BR 343, km 3,5. Bairro Meladão. Campus Amílcar Ferreira Sobral. Floriano-PI, Brasil (CEP 64808-605).
}

Resumo. O mercado brasileiro de pimentas ornamentais tem apresentado expressivo crescimento, exigindo o conhecimento de características relacionadas a essa finalidade. 0 presente trabalho teve como objetivo analisar a diversidade genética em pimentas Capsicum annuum L. (Solanaceae) utilizando-se de características qualitativas e quantitativas para a seleção de genótipos promissores para uso ornamental. 0 experimento foi conduzido em casa de vegetação em delineamento inteiramente casualizado com 11 genótipos e três repetições. Foram empregadas 20 características qualitativas e nove quantitativas. Utilizou-se análise multivariada e os dados qualitativos e quantitativos foram submetidos a agrupamentos hierárquicos pelo Método Ward e UPGMA, respectivamente. A análise conjunta das variáveis foi obtida com base no Algoritmo de Gower. No agrupamento com os dados qualitativos obtiveram-se seis grupos e para os dados quantitativos houve a formação de cinco grupos, sendo indicativo de diversidade genética entre os genótipos estudados. Na análise conjunta, foram formados cinco grupos possibilitando a recomendação dos genótipos GEN40, GEN57, GEN75, GEN77,

Recebido

$01 / 06 / 2020$

Aceito

$17 / 10 / 2020$

Disponível on line $18 / 10 / 2020$

Publicado $31 / 12 / 2020$

Acesso aberto

ISSN 2359-1412/RBGAS-2020-0089/2020/7/17/9/1165

Rev. Bras. Gest. Amb. Sustent.

http://revista.ecogestaobrasil.net 
GEN80 e GEN85 como os mais promissores para fins ornamentais por reunirem atributos de relevante valor estético.

Palavras-chave: Pimentas; Análise multivariada; Algoritmo de Gower; Melhoramento genético vegetal.

Abstract. Genetic diversity in promising Capsicum annuum genotypes for ornamental use. The Brazilian market for ornamental peppers has grown significantly, requiring knowledge of characteristics related to this purpose. The present work aimed to analyze the genetic diversity in Capsicum annuum L. (Solanaceae) peppers using qualitative and quantitative characteristics for the selection of promising genotypes for ornamental use. The experiment was carried out in a greenhouse in a completely randomized design with 11 genotypes and three replications. Twenty qualitative and nine quantitative characteristics were used. Multivariate analysis was used and qualitative and quantitative data were submitted to hierarchical groupings by the Ward and UPGMA method, respectively. The joint analysis of the variables was obtained based on the Gower algorithm. In the grouping with the qualitative data, six groups were obtained and for the quantitative data, five groups were formed, being indicative of genetic diversity among the studied genotypes. In the joint analysis, five groups were formed allowing the recommendation of the genotypes GEN40, GEN57, GEN75, GEN77, GEN80 and GEN85 as the most promising for ornamental purposes because they gather attributes of relevant aesthetic value.

Keywords: Peppers; Multivariate analysis; Gower's algorithm; Plant breeding.

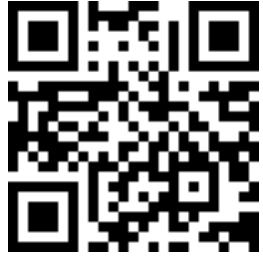

ORCID

(ㄱ) 0000-0001-9131-1936

Laís dos Santos Neri da Silva

D 0000-0002-9532-9057

Gabriela Corrêa

Morais

(ㄷ) 0000-0002-4463-3139

Lucas da Silva Costa

(1) 0000-0003-1971-7725

Jéssica Fernanda

Ferreira dos Santos

(D) 0000-0002-6090-8139

Camila Maria Ribeiro

da Silva Filha

(b) 0000-0002-9987-0043

Raimundo Nonato

Oliveira Silva

\section{Introdução}

O gênero Capsicum é representado pela ampla diversidade de pimentas e pimentões, cuja importância econômica revela-se promissora devido à versatilidade de aplicações na culinária mundial, medicina, indústria farmacêutica e uso ornamental (Rêgo et al., 2012; Gomes et al., 2019). A praticidade do cultivo de pimentas em vasos e os atributos estéticos relacionados ao porte harmônico, folhas e frutos pequenos e coloridos (Neitzke et al., 2010; Neitzke et al., 2016) favorecem sua aceitação e comercialização demonstrando seu potencial para o setor de ornamentação (Silva et al., 2015b).

Apesar da expressiva importância econômica, existem poucas cultivares de pimentas ornamentais (Neitzke et al., 2010; Costa et al., 2019). 0 desenvolvimento de cultivares de pimentas ornamentais para atender a demanda do consumo requer aperfeiçoamento e inovação de modo a proporcionar rápido retorno financeiro e ampliar a competividade no setor de paisagismo (Costa et al., 2017; Costa et al., 2019).

Os programas de melhoramento genético buscam identificar e selecionar genótipos que atendem à finalidade ornamental explorando a diversidade genética existente (Rêgo e Rêgo, 2018) através do uso de características relacionadas à arquitetura geral da planta, tamanho de fruto e caracteres harmônicos de flores (Fortunato et al., 2019). Atividades de caracterização morfológica fornecem subsídios para programas de 
melhoramento adotar estratégias de uso do potencial ornamental de pimentas (Neitzke et al., 2010; Ferraz et al., 2016).

O emprego de características quantitativas e qualitativas em procedimentos de caracterização e avaliação possibilita a distinção entre genótipos (Quintal et al., 2012), proporcionando a seleção de genitores para cruzamentos visando objetivos específicos. Entretanto, o grande volume de dados quantitativos e qualitativos impede a análise e interpretação completa dos resultados (Rocha et al., 2010). A análise conjunta dos dados, proposta por Gower (1971), é uma alternativa para contornar esse problema, uma vez que, permite analisar concomitantemente um conjunto de variáveis gerando resultados consistentes e maiores informações sobre a variabilidade genética existente em bancos de germoplasma (Quintal et al., 2012).

Diante disso, o presente trabalho teve como objetivo analisar a diversidade genética em pimentas Capsicum annuum L. (Solanaceae) utilizando-se de características qualitativas e quantitativas para a seleção de genótipos promissores para uso ornamental.

\section{Material e métodos}

O experimento foi conduzido em casa de vegetação, na Universidade Federal do Piauí, Campus Amílcar Ferreira Sobral (UFPI/CAFS), no Município de Floriano, latitude $06^{\circ} 46^{\prime} 01^{\prime \prime} \mathrm{S}$ e longitude $43^{\circ} 01^{\prime} 22^{\prime \prime} \mathrm{W}$. Foi utilizado delineamento inteiramente casualizado com três repetições e 11 genótipos de C. annuum (GEN14, GEN16, GEN38, GEN40, GEN53, GEN57, GEN75, GEN77, GEN80, GEN85 e GEN86) pertencentes a Coleção de Germoplasma de Capsicum UFPI/CAFS. Considerou-se como parcela experimental um vaso contendo uma planta.

Os genótipos foram semeados em recipientes plásticos de $150 \mathrm{~mL}$ contendo substrato comercial Garden Plus ${ }^{\circledR}$ sem aditivos químicos e transplantados, ao atingirem de quatro a seis pares de folhas definitivas, para vasos de $2,8 \mathrm{~L}$ preenchidos com substrato vegetal composto por turfa, sendo aditivado com fertilizantes mineral, $(\mathrm{N}=0,02 \%$, $\mathrm{P}_{2} \mathrm{O}_{5}=0,08 \%$ e $\left.\mathrm{K}_{2} \mathrm{O}=0,04 \%\right)$ e calcário calcítico (3,0\%). 0 manejo da cultura seguiu recomendações sugeridas por Filgueira (2013).

Utilizou-se 20 características qualitativas e nove quantitativas, conforme a lista de descritores para Capsicum disponibilizadas pelo International Plant Genetic Resources Institute (IPGRI, 1995). Os caracteres qualitativos utilizados foram: cor do caule, antocianina do nó, forma do caule, pubescência do caule, hábito de crescimento, densidade dos ramos, densidade das folhas, cor da folha, forma da folha, número de flores por axila, posição da flor, cor da corola, cor da mancha da corola, forma da corola, cor das anteras, cor do filete, cor do fruto intermediário, cor do fruto maduro, forma do fruto e forma do ápice do fruto. Os caracteres qualitativos foram obtidos a partir da moda de cinco observações por planta.

Foram empregados os seguintes caracteres quantitativos: altura da planta, diâmetro da copa, comprimento da folha, largura da folha, comprimento do fruto, largura do fruto, comprimento do pedicelo, dias para floração e dias para frutificação. Considerando os dados quantitativos, utilizou-se a média da parcela para cada caraterística. Para os descritores referentes à folha e fruto, as mensurações foram realizadas com auxílio de um paquímetro digital, em $\mathrm{mm}$, em cinco folhas e cinco frutos de cada planta. A altura da planta e diâmetro da copa foram medidas em $\mathrm{cm}$, utilizando-se fita métrica.

$\mathrm{Na}$ análise estatística individual dos dados qualitativos, aqueles que apresentaram polimorfismo foram submetidos à análise de divergência genética. A matriz de dissimilaridade foi gerada com base no complemento do coeficiente de coincidência simples. Para os dados quantitativos foi utilizada, como medida de dissimilaridade, a Distância de Mahalanobis. Enquanto que a matriz de distância genética para a análise 
conjunta das variáveis quantitativas e qualitativas foi obtida através do Algoritmo de Gower (1971).

A análise separada dos dados qualitativos foi realizada como auxílio do programa GENES (Cruz et al., 2013) e a análise dos dados quantitativos e análise conjunta foram realizadas no Software R Studio versão 3.5.2.

\section{Resultados}

Considerando os caracteres qualitativos houve a formação de seis grupos, constatando-se variabilidade genética entre os genótipos estudados (Figura 1). 0 grupo I reuniu os genótipos GEN57, GEN77 e GEN80 que possuem cor da folha verde escura destacando-se entre os frutos. A característica cor do fruto no estádio intermediário revelou variação de cor de tons amarelados a alaranjados adquirindo coloração vermelha na maturação final. 0 grupo II alocou os genótipos GEN16 e GEN38 caracterizados pela coloração dos frutos imaturos verdes, sem variação de cor nesse período. No entanto, quando maduros, seus frutos apresentam coloração alaranjada e amarelada, respectivamente.

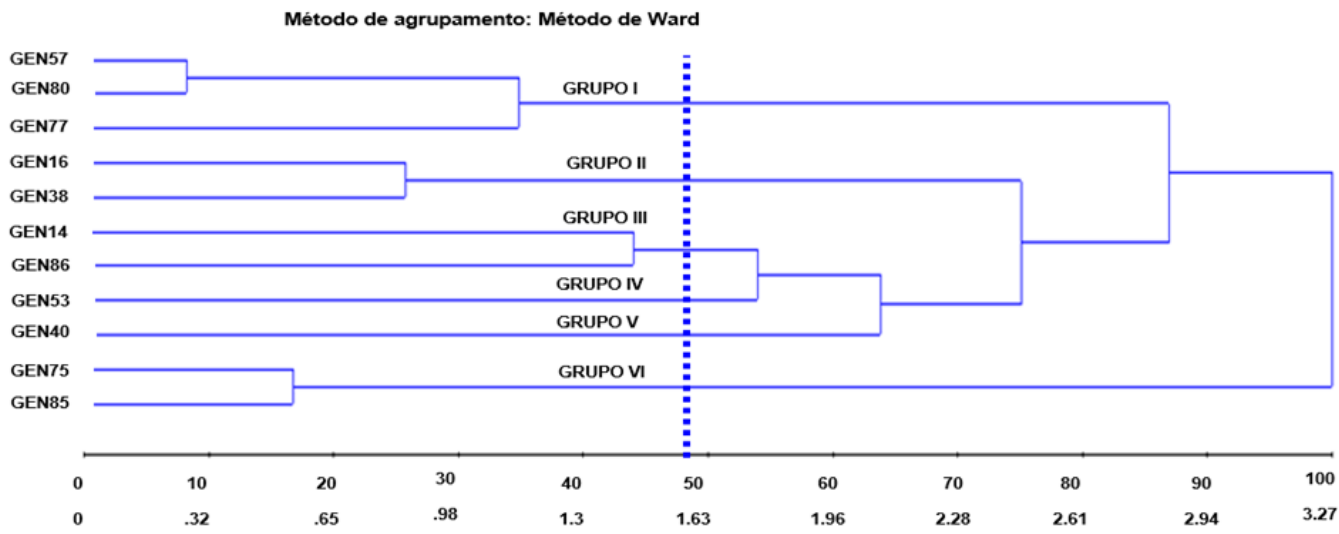

Figura 1. Dendrograma de dissimilaridade genética entre 11 genótipos de Capsicum annuum, obtido pelo método de agrupamento Ward com base em 20 características qualitativas. Floriano-PI, Brasil, 2018.

O grupo III reuniu o GEN14 e GEN86. Ambos os genótipos não possuem pigmentação na corola e anteras. O GEN14 possui flores de formato acampanulado e o GEN86 flores pendentes. 0 genótipo GEN53 é o único, dentre aqueles estudados, que possui pubescência do caule do tipo intermediaria. O GEN40 também ficou isolado dos outros genótipos por possuir, dentre outros caracteres, pétalas brancas com margens de coloração púrpura. O grupo VI reuniu os genótipos GEN75 e GEN85 que possuem antocianina do nó, além de corola e anteras roxas.

Com a utilização dos caracteres quantitativos foi possível a formação de cinco grupos (Figura 2), indicativo de diversidade genética entre os genótipos. No grupo I foram alocados os genótipos GEN14, GEN16 e GEN40, com diâmetro da copa de 38,33 cm, $41,67 \mathrm{~cm}$ e 44,00 cm, respectivamente. 0 grupo II, que reuniu os genótipos GEN57, GEN77 e GEN80, foi concordante com o agrupamento formado pelos dados qualitativos. Esses 
genótipos possuem dimensões de frutos que variaram entre $13,98 \mathrm{~mm}$ e $14,51 \mathrm{~mm}$ e $11,67 \mathrm{~mm}$ e 12,03 $\mathrm{mm}$ para comprimento e largura do fruto, respectivamente.

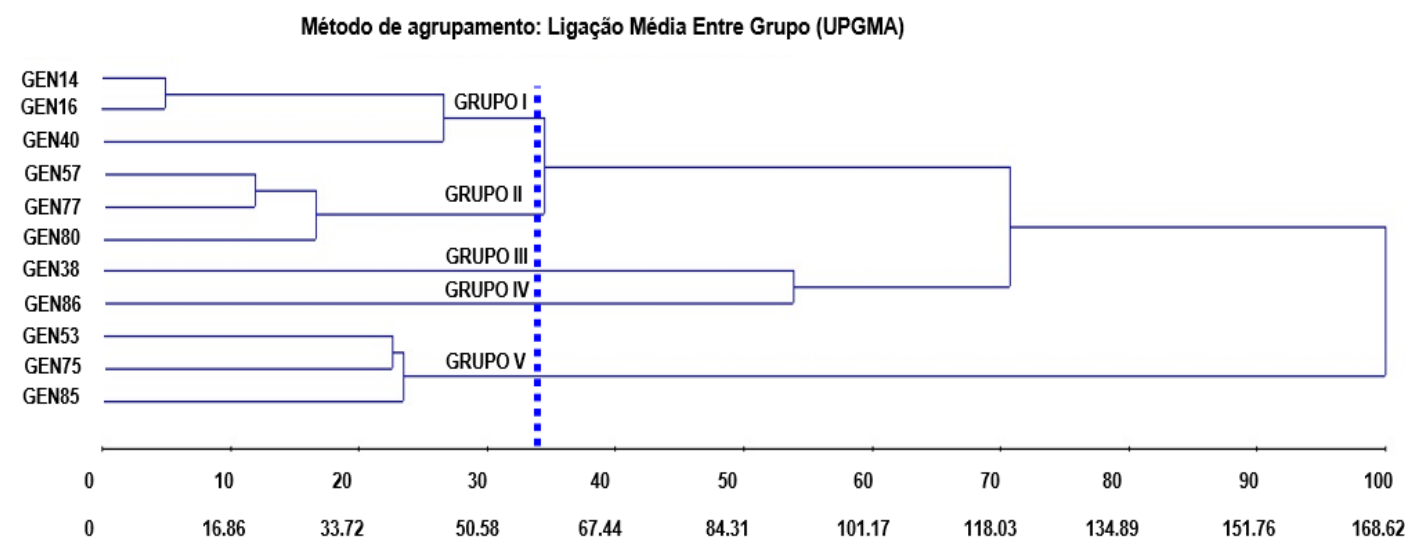

Figura 2. Dendrograma de dissimilaridade genética entre 11 genótipos de Capsicum annuum obtido pelo método de UPGMA por meio da distância de Mahalanobis com base em nove descritores quantitativos. Floriano-PI, Brasil, 2018.

O GEN38 destaca-se entre os demais por possui comprimento da folha de $63,28 \mathrm{~mm}$. O genótipo GEN86 ficou sozinho possuir maior valor para altura da planta $(39,00 \mathrm{~cm})$ em relação aos demais genótipos estudados. No grupo V, formado pelos genótipos GEN53, GEN75 e GEN85, verificou-se tamanhos reduzidos para a característica altura da planta, com valores entre $22,33 \mathrm{~cm}$ e $32,00 \mathrm{~cm}$. Quanto ao comprimento de fruto, verificou-se variação de $8,91 \mathrm{~mm}$ a $13,54 \mathrm{~mm}$, enquanto que a largura do fruto compreendeu valores de 5,03 $\mathrm{mm}$ a 6,32 $\mathrm{mm}$.

Considerando então a análise conjunta dos dados foi possível verificar a formação de cinco grupos (Figura 3). 0 grupo I foi constituído pelo GEN86, sendo concordante com o agrupamento de dados quantitativos (Figura 2). Esse genótipo possui os maiores valores para comprimento $(51,58 \mathrm{~mm})$ e largura do fruto $(18,22 \mathrm{~mm})$. 0 GEN86 possui, ainda, frutos pendentes.

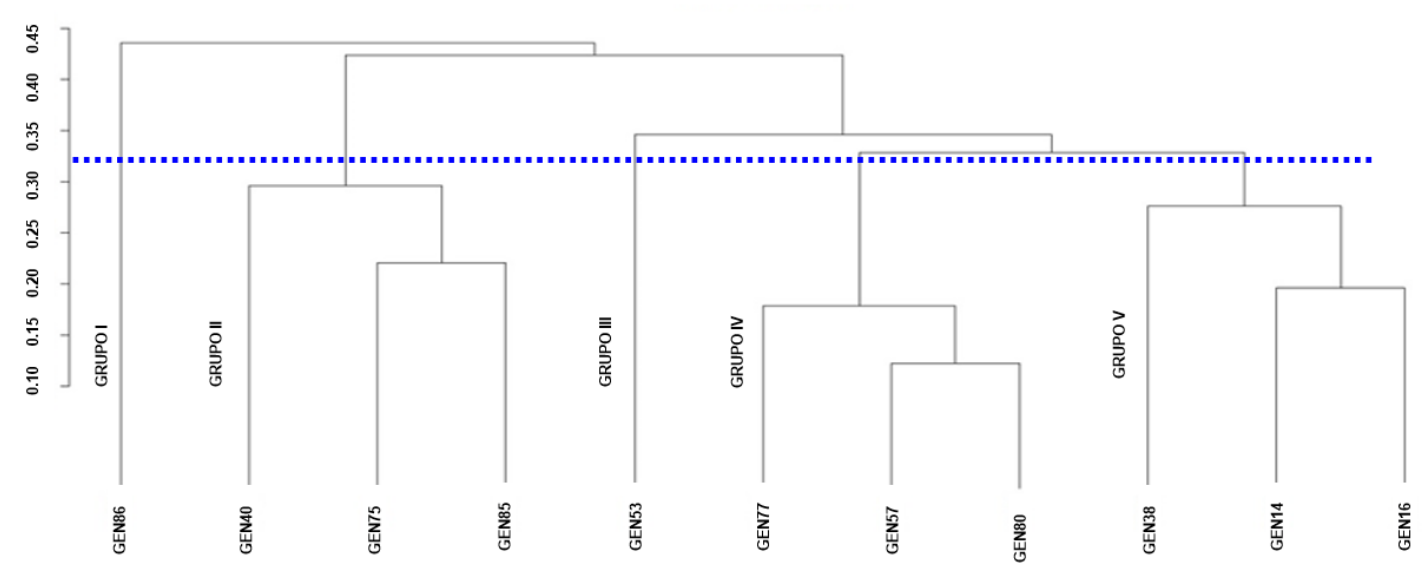

Figura 3. Dendrograma de 11 genótipos de Capsicum annuum utilizando-se a distância de Gower para variáveis qualitativas e quantitativas avaliadas conjuntamente. Floriano-PI, Brasil, 2018. 
O grupo II, representado pelos genótipos GEN40, GEN75 e o GEN85, possui valores médios para o comprimento do pedicelo variando entre 16,83 e 18,92 $\mathrm{mm}$. Os genótipos do referido grupo possuem flores parciais ou totalmente roxas. 0 grupo III compreendeu o GEN53, sendo concordante com o agrupamento obtido para os dados qualitativos. Este genótipo possui precocidade para a floração e frutificação, 85 e 103 dias, respectivamente. Entretanto, o GEN53 não possui mudança de cor dos frutos durante a maturação.

O Grupo IV alocou os genótipos GEN57, GEN77 e GEN80 que possuem a característica altura da planta com variação de $24,67 \mathrm{~cm}$ a $27,00 \mathrm{~cm}$. Além disso, esses genótipos possuem frutos eretos, coloração intensa e formato de fruto arredondado. 0 grupo V reuniu os genótipos GEN14, GEN16 e GEN38 que possuem diâmetro da copa variando entre $38,33 \mathrm{~cm}$ e 42,33 cm. Os frutos desses genótipos possuem coloração verde durante a fase intermediária de maturação e, ao final desse processo, os frutos passam a adquirir coloração vermelha (GEN14), laranja (GEN16) e amarela (GEN38).

\section{Discussão}

A expressiva mudança de cor do fruto durante todo o estádio intermediário de maturação conferiu aos genótipos GEN57, GEN77 e GEN80 uma característica atrativa para fins ornamentais. O GEN16 e GEN38 possuem frutos imaturos verdes e na maturação final atingem a coloração alaranjada e amarelada, respectivamente concordando com Carvalho et al. (2006) que afirmam que pimentas usadas como plantas ornamentais podem também assumir frutos de diferentes tons de amarelo e laranja.

Flores sem pigmentação nas pétalas, como formato acampanulado e pendentes atribuídas ao GEN14 e GEN86 dificulta a sua visualização na planta tornado essas características pouco atraentes e de irrelevante valor estético. A presença de pelos na região caulinar do GEN53 pode estar relacionada, segundo Neitzke et al. (2014), com a tolerância ao ataque de pragas, sendo um atributo interessante considerando que nos padrões de Veiling Holambra (2020), pimentas ornamentais acometidas por doenças têm sua comercialização inviabilizada.

0 padrão de flor do GEN40, pétalas brancas com bordas púrpuras, possui atributo ornamental, corroborando com Silva et al. (2015a), que afirmam que a presença de pigmentos contrastando com as pétalas exprime elevado valor estético. A presença de antocianina em regiões específicas, como caule e flores, do GEN75 e GNE85 são importantes para o mercado de pimentas ornamentais, pois, desperta a atenção do público consumidor.

Características qualitativas são interessantes para verificar genótipos com potencial ornamental (Neitzke et al., 2010), pois são de fácil distinção em relação às quantitativas em virtude do tipo de herança, sendo governada por um ou poucos genes com influência mínima do ambiente (Monteiro et al., 2010). Considerando os caracteres qualitativos estudados, os genótipos GEN16, GEN38, GEN40, GEN57, GEN75, GEN77, GEN80 e GEN85 são promissores para fins ornamentais.

Para os caracteres quantitativos, a característica diâmetro da copa tem considerável relevância para plantas ornamentais, pois, segundo Lima et al. (2013), a área foliar é responsável por ocupar espaço do vaso, possibilitando sua utilização como planta ornamental. Além disso, as pimentas ornamentais são classificadas comercialmente de acordo com a capacidade de cobertura e disposição da folhagem no vaso (Veiling Holambra, 2020).

Os frutos reduzidos dos genótipos GEN57, GEN77 e GEN80 são relevantes para o mercado consumidor de pimentas ornamentais, uma vez que são preferíveis frutos com menores dimensões (Silva et al., 2015a) proporcionado harmonia com a planta envasada, conferindo-lhe valor ornamental (Melo et al., 2014). 
Em relação ao GEN38, embora as dimensões das folhas estejam associadas a intercepção e distribuição da luz durante o processo de fotossíntese (Lopes e Lima, 2015), folhas maiores dificulta a visualização dos frutos, não sendo, portanto, interessante do ponto de vista ornamental.

O maior porte do GEN86, em relação aos demais genótipos desse estudo, impossibilita seu cultivo em vasos. Entretanto, mesmo não sendo utilizados para fins ornamentais, genótipos com esses atributos, conforme Neitzke et al. (2010), podem ser empregados em jardinagem. Por outro lado, genótipos como GNE53, GEN75 e GEN85 que possuem tamanhos reduzidos para altura da planta são apreciados no segmento de ornamentação, sendo indicadas para cultivo em vasos devido ao fácil manejo e durabilidade na produção (Neitzke et al., 2016).

Observou-se que a análise dos dados qualitativos formou mais grupos do que aquela utilizando dados quantitativos. Os caracteres quantitativos são importantes na discriminação de genótipos favoráveis em programas de melhoramento (Moura et al., 2010), porém, os descritores qualitativos são indispensáveis na distinção e obtenção de genótipos promissores a uso ornamental, pois, estão associados a atributos de maior apelo estético como coloração dos frutos, presença de pigmentos dentre outros (Neitzke et al., 2010).

Na análise conjunta, o GEN86 ficou isolado dos demais genótipos por possui frutos maiores e pendentes não sendo atrativos para o mercado de ornamentação visto que frutos com tais atributos tendem a ficar escondidos entre as folhas sendo difícil a sua percepção (Melo et al., 2014).

O tamanho do pedicelo nos genótipos GEN40, GEN75 e GEN85 é uma característica que deve ser considerada no setor de ornamentação pois, de acordo com Melo et al. (2014), o tamanho dos pedicelos em pimentas ornamentais proporciona maior destaque dos frutos entre as folhas, agregando valor estético. Além disso, traços florais parciais ou totalmente pigmentados dos genótipos supracitados expressa suavidade e atratividade. Conforme Silva et al. (2015a) variações de cores nas pétalas e anteras exibem caráter ornamental.

Características de precocidade para floração e maturação conferida ao GEN53 é atrativa para fins ornamentais, uma vez que os frutos são os primeiros a despertar atenção dos consumidores de pimenteiras (Silva et al., 2015a). Entretanto, a ausência de variação de cores do fruto na maturação torna esse genótipo não promissor esteticamente.

A altura da planta para os genótipos GEN57, GEN77 e GEN80 os tornam promissores para o mercado, pois, estão de acordo com os padrões estabelecidos por Veiling Holambra (2020), que estabelece a altura de pimentas ornamentais entre 20,00 cm e $32,00 \mathrm{~cm}$ ideias para comercialização. Outros atributos estéticos de frutos desses genótipos como posição ereta, coloração e formato os torna atrativos na ornamentação, pois são facilmente observados na planta.

O GEN14, GEN16 e GEN38 possuem diâmetro da copa capaz de proporcionar equilíbrio com a arquitetura da planta, porém a ausência de mudanças de coloração durante a maturação dos frutos, sem destaque entre as folhas, não confere valor ornamental.

Com base na análise conjunta recomendam-se para serem utilizados em programas de melhoramento genético, com finalidade ornamental, os genótipos GEN40, GEN57, GEN75, GEN77, GEN80 e GEN85 (Figura 4). Esses genótipos possuem, dentre outros atributos indicado para fins de ornamentação, pequeno porte, diâmetro da copa harmônico com o vaso, frutos pequenos e mudança de cor durante a maturação, além de flores pigmentadas e eretas contrastantes com a folhagem. 


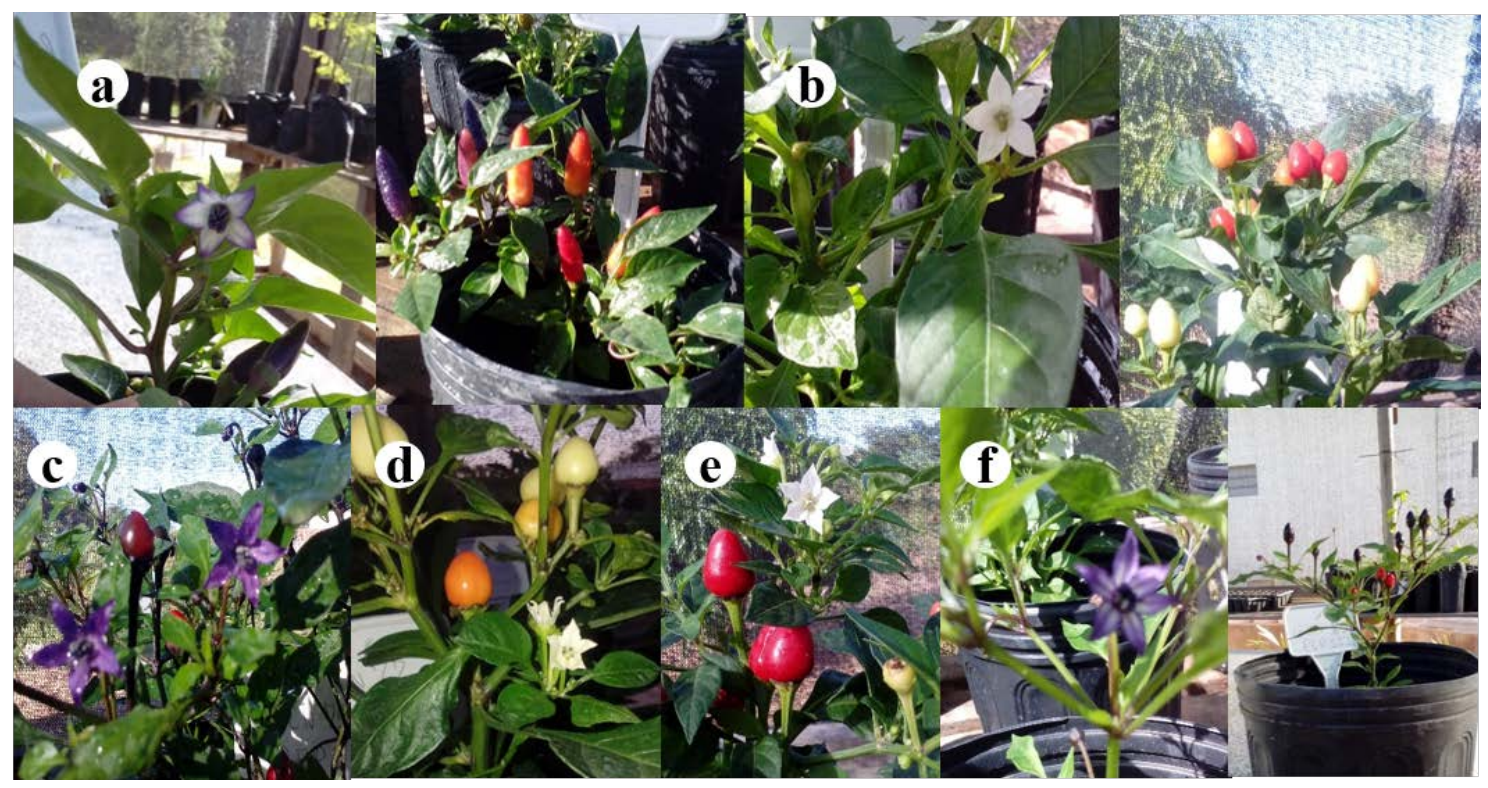

Figura 4. Genótipos de Capsicum annuum com potencial ornamental selecionados com base na análise conjunta utilizando algoritmo de Gower. (a) GEN40, (b) GEN57, (c) GEN75, (d) GEN77, (e) GEN80, (f) GEN85. Floriano-PI, Brasil, 2018.

Seguramente, a análise de descritores quantitativos e qualitativos contribui para a seleção de genótipos promissores em programas de melhoramento genético (Neitzke et al., 2010). Entretanto, a análise conjunta desses dados fornece informações mais precisas sobre a compreensão da diversidade genética (Rocha et al., 2010), propiciando estratégias eficientes de uso do germoplasma disponível em programas de melhoramento genético (Moura et al., 2010).

\section{Conclusões}

Verificou-se diversidade genética entre os genótipos de pimentas estudados, sendo os mais indicados para programas de melhoramento para fins ornamentais, por reunirem atributos de relevante valor estético, os genótipos GEN40, GEN57, GEN75, GEN77, GEN80 e GEN85.

\section{Agradecimentos}

À Universidade Federal do Piauí - Campus Amílcar Ferreira Sobral (UFPI-CAFS) pela estrutura necessária à realização da pesquisa.

\section{Conflito de interesses}

Os autores declaram não haver conflito de interesses.

\section{Referências}

Carvalho, S. I. C.; Bianchetti, L. B.; Ribeiro, C. S. C.; Lopes, C. A. Pimentas do gênero Capsicum no Brasil. Brasília: Embrapa Hortaliças, 2006. 
Costa, E.; Santo, T. L. E.; Batista, T. B.; Curi, T. M. R. C. Diferentes tipos de ambiente protegido e substratos na produção de pimenteiras. Horticultura Brasileira, v. 35, n. 3, p. 458-466, 2017. https://doi.org/10.1590/S0102-053620170324

Costa, G. N.; Silva, B. M. P.; Lopes, A. C. A.; Carvalho, L. C. B.; Gomes, R. L. F. Selection of pepper accessions with ornamental potential. Revista Caatinga, v. 32, n. 2, p. 566-574, 2019. https://doi.org/10.1590/1983-21252019v32n230rc

Cruz, C. D. GENES: a software package for analysis in experimental statistics and quantitative genetics. Acta Scientiarum. Agronomy, v. 35, n. 3, p. 271-276, 2013. https://doi.org/10.4025/actasciagron.v35i3.21251

Ferraz, R. M.; Ragassi, C. F.; Heinrich, A. G.; Lima, M. F.; Peixoto, J. R.; Reifschneider, F. J. B. Caracterização morfoagronômica preliminar de acessos de pimentas cumari. Horticultura Brasileira, v. 34, n. 4, p. 498-506, 2016. https://doi.org/10.1590/S0102-053620160408

Filgueira, F. A. R. Novo manual de olericultura: agrotecnologia moderna na produção e comercialização de hortaliças. Viçosa: UFV, 2013.

Fortunato, F. L. G.; Rêgo, E. R.; Carvalho, M. G.; Santos, C. A. P.; Rêgo, M. M. Genetic diversity in ornamental pepper plants. Comunicata Scientiae, v. 10, n. 3, p. 364-375, 2019. https://doi.org/10.14295/cs.v10i3.2843

Gomes, G. P.; Baba, Y. V.; Santos, O. P. Combinations of distance measures and clustering algorithms in pepper germplasm characterization. Horticultura Brasileira, v. 37, n. 2, p. 172-17, 2019. https://doi.org/10.1590/s0102-053620190207

Gower, J. C. A general coefficient of similarity and some of its properties. Biometrics, v. 27, n. 4, p. 857-871, 1971. https://doi.org/10.2307/2528823

IPGRI - International Plant Genetic Resources Institute. Descriptores para Capsicum (Capsicum spp). Roma: IPGRI, 1995.

Lima, I. B.; Santos, A. B.; Fonseca, J. J. S.; Takane, R. J.; Lacerda, C. F. Pimenteira ornamental submetida a tratamentos com daminozide em vasos com fibra de coco ou areia. Semina: Ciências Agrárias, v. 34, n. 6, p. 3597-3610, 2013. https://doi.org/10.5433/16790359.2013v34n6Supl1p3597

Lopes, N. F.; Lima, M. G. S. Fisiologia da produção. Viçosa: UFV, 2015.

Melo, L. F.; Gomes, R. L. F; Silva, V. B.; Monteiro, E. R.; Lopes, A. C. A.; Peron, A. P. Potencial ornamental de acessos de pimenta. Ciência Rural, v. 44, n. 11, p. 2010-2015, 2014. https://doi.org/10.1590/0103-8478cr20131306

Monteiro, E. R.; Bastos, E. M.; Lopes, A. C. A.; Gomes, R. L. F.; Nunes, J. A. R. Diversidade genética entre acessos de espécies cultivadas de pimentas. Ciência Rural, v. 40, n. 2, p. 288-293, 2010. https://doi.org/10.1590/S0103-84782010005000015

Moura, M. C. C. L.; Gonçalves, L. S. A.; Sudré, C. P.; Rodrigues, R.; Amaral Júnior, A. T.; Pereira, T. N. S. Algoritmo de Gower na estimativa da diversidade genética em germoplasma de pimentas. Horticultura Brasileira, v. 28, n. 2, p. 155-161, 2010. https://doi.org/10.1590/S0102-05362010000200003

Neitzke, R. S.; Barbieri, R. L.; Rodrigues, W. F.; Côrrea, I. V.; Carvalho, F. I. F. Dissimilaridade genética entre acessos de pimenta com potencial ornamental. Horticultura Brasileira, v. 28, n. 1, p. 47-53, 2010. https://doi.org/10.1590/S0102-05362010000100009 
Neitzke, R. S.; Barbieri, R. L.; Vasconcelos, C. S.; Fischer, S. Z.; Vilela, J. C. B.; Castro, C. M. Caracterização morfológica e estimativa da distância genética de acessos de pimenta do banco ativo de germoplasma de Capsicum da Embrapa Clima Temperado. Pelotas: Embrapa Clima Temperado, 2014.

Neitzke, R. S.; Fischer, S. Z.; Vasconcelos, C. S.; Barbieri, R. L.; Treptow, R. O. Pimentas ornamentais: aceitação e preferências do público consumidor. Horticultura Brasileira, v. 34, n. 1, p. 102-109, 2016. https://doi.org/10.1590/S0102-053620160000100015

Quintal, S. S. R.; Viana, A. P.; Gonçalves, L. S. A.; Pereira, M. G.; Amaral Júnior, A. T. Divergência genética entre acessos de mamoeiro por meio de variáveis morfoagronômicas. Semina: Ciências Agrárias, v. 33, n. 1, p. 131-142, 2012. https://doi.org/10.5433/1679-0359.2012v33n1p131

Rêgo, E. R.; Finger, F. L.; Rêgo, M. M. Types, uses and fruit quality of Brazilian chili peppers. In: Kralis, J. F. (Org.). Spices: Types, uses and health benefits. Nova York: Nova Science, 2012. p. 131-144.

Rêgo, E. R.; Rêgo, M. M. Ornamental pepper. In: Huylenbroeck, J. V. Ornamental crops. Cham: Springer, 2018. p. 529-565. https://doi.org/10.1007/978-3-319-90698-0_22

Rocha, M. C.; Gonçalves, L. S. A.; Rodrigues, R.; Silva, P. R. A.; Carmo, M. G. F.; Abboud, A. C. S. Uso do algoritmo de Gower na determinação da divergência genética entre acessos de tomateiro do grupo cereja. Acta Scientiarum. Agronomy, v. 32, n. 3, p. 423-431, 2010. https://doi.org/10.4025/actasciagron.v32i3.4888

Silva. C. Q.; Jasmim, J. M.; Santos, J. O.; Bento, C. S.; Sudré, C. P.; Rodrigues, R. Phenotyping and selecting parents for ornamental purposes in pepper accessions. Horticultura Brasileira, v. 33, n. 1, p. 66-73, 2015a. https://doi.org/10.1590/S0102053620150000100011

Silva, F. C.; Ribeiro, W. S.; Costa, L. C.; Pinto, C. M. F.; Finger, F. L. Evaluation of substrates on the production of ornamental Capsicum. Acta Horticulturae, v. 1, n. 51, p. 115-120, 2015b. https://doi.org/10.17660/ActaHortic.2015.1060.15

Veiling Holambra. Flores e plantas ornamentais. Pimenta ornamental de vaso. 2020. Disponível em: <http://veiling.com.br/uploads/padrao/pimenta-ornamental-po.pdf>. Acesso em: 25 mar. 2020.

Informação da Licença: Este é um artigo Open Access distribuído sob os termos da Licença Creative Commons Attribution, que permite uso irrestrito, distribuição e reprodução em qualquer meio, desde que a obra original seja devidamente citada. 